\title{
SAFETY OF OMBITASVIR/PARITAPREVIR/RITONAVIR+DASABUVIR IN CHRONIC HEPATITIS C PATIENTS WITH HCV GENOTYPE 1 INFECTION
}

\author{
TOMASZ TATARA ${ }^{1}$, MARTA DĄBROWSKA-BENDER ${ }^{2 *}$, ANETA DUDA-ZALEWSKA ${ }^{1}$ \\ and ANNA STANISZEWSKA ${ }^{3}$
}

'Department of Public Health, Medical University of Warsaw, Banacha 1A, 02-097 Warszawa, Poland

${ }^{2}$ Department of Clinical Nutrition, Medical University of Warsaw, Erazma Ciołka 27, 01-445 Warszawa, Poland

${ }^{3}$ Department of Experimental and Clinical Pharmacology, Medical University of Warsaw, Banacha 1B, 02-097 Warszawa, Poland

\begin{abstract}
The assessment of the safety profile of ombitasvir/paritaprevir/ritonavir+dasabuvir in adult chronic hepatitis $\mathrm{C}$ patients with confirmed HCV genotype 1 presence. Evaluation of clinical safety based on the results of primary studies found in the systematic review. The following literature databases were searched: Medline, Embase, Cochrane Library and others. Finally, two clinical trials met the inclusion criteria. The study included untreated patients (SAPPHIRE I) or patients after unsuccessful therapy (SAPPHIRE II), with genotype 1 infection. In patients without prior treatment, the prevalence of the reported adverse events was in general statistically significantly greater in the group on therapy $3 \mathrm{D}+\mathrm{RBV}$ compared to the placebo group. No statistically significant differences were observed in relation to the risk of serious adverse events or therapy discontinuance due to adverse events. In patients after unsuccessful therapy, the prevalence of the reported adverse events was statistically significantly greater in the group on therapy $3 \mathrm{D}+\mathrm{RBV}$ compared to the placebo group. During the $3 \mathrm{D}+\mathrm{RBV}$ itching was statistically significantly more frequently reported in the placebo group. Compared to the other adverse events, no statistically significant differences were observed. Interferon-free therapies provide a safe therapeutic option in the population of adult patients with chronic genotype 1 hepatitis $\mathrm{C}$, both those untreated and after unsuccessful two-drug PegIFN $\alpha$-based therapy, patients with HIV co-infection and patients after liver transplantation.
\end{abstract}

Keywords: safety, ombitasvir/paritaprevir/ritonavir+dasabuvir, hepatis C

Chronic hepatitis $\mathrm{C}$ is defined as the hepatic tissue inflammation caused by hepatitis $\mathrm{C}$ virus (HCV), during which the RNA HCV remains in the blood for $>6$ month and necrotic-inflammatory lesions are observed in liver biopsy specimens (1).

In most patients, the HCV infection is asymptomatic and accompanied by slow disease progression. In $50-85 \%$ of patients, the infection goes into a chronic condition which gradually leads to hepatic insufficiency. During the acute phase, some patients develop jaundice accompanied by symptoms of a systemic viral infection, eg weakness, reduced appetite, nausea, flatulence and low severity pain in the right subcostal region. Subacute or fulminant hepatitis $\mathrm{C}$ is rarely observed $(<1 \%)(1)$.

It is estimated that currently 120 to 170 million people in the world are infected with hepatitis C, while mortality due to liver diseases associated with hepatitis $\mathrm{C}$ is over 350 thousand people a year (2). The highest prevalence (over 3.5\%) is recorded in Central and Eastern Asia, North Africa as well as in the Middle East. The regions with the lowest endemism are North America, Australia, Western and Northern Europe (2). According to a report presented by the European Center for Disease Prevention and Control in 2015, 34651 laboratory-confirmed $\mathrm{HCV}$ cases were registered in 28 European countries, which corresponds to an average annual incidence of 8.6 cases per 100 thousand residents (3).

Epidemiological research conducted as part of the recently completed research project "Prevention of HCV infection" co-financed by Switzerland and implemented by the National Institute of Public Health - National Institute of Hygiene (NIZP-PHZ)

\footnotetext{
* Corresponding author: e-mail: marta.dbender@gmail.com
} 
on a sample of 23 thousand people showed that in the years $2012-2016$ about $1.1 \%$ of respondents possessed specific anti-HCV antibodies that indicate contact with the virus, and about $0.47 \%$ were found to contain the genetic material of the virus (HCV RNA) in the blood, which is synonymous with the statement active disease state. Taking into account the interest obtained in the study, the authors estimate that about 165 thousand adults in Poland may have a chronic Hepatitis $\mathrm{C}$, with the possible spread of the result, the number may range from 127 up to 190 thousand (4).

Current data referring to the prevalence of individual $\mathrm{HCV}$ genotypes in the polish population come from the EpiTer questionnaire study, which collected results from 29 diagnostic centers located in 15 polish voivodships. In total, the analysis covered 9.800 patients with hepatitis $\mathrm{C}$ diagnosed in 2013-2016 (5).

The report shows that HCV by GT1 is the most frequent aetiological factor of hepatitis $\mathrm{C}$ in Poland and in 2013-2016 was responsible for about $85 \%$ of cases. The next in terms of frequency were GT3 ( $11 \%$ of patients), GT4 (3\%) and GT2 $(0.2 \%)$, while GT5 and 6 were reported only in isolated cases (0.1\%) (5).

The aim of the Hepatitis C treatment is complete eradication of HCV infection and, consequently, stopping or retardation of histological changes, as well as limiting the risk of HCC development and transferring infection to other people. In clinical practice, the measure of the effectiveness of therapy is to obtain a virological response, the assessment of which is based on the measurement of HCV RNA levels in the blood at specific times of therapy and after its completion. SVR (sustained virologic response), undetectable viral load, usually measured at 12 or less frequently at week 24 after the end of treatment, strongly correlates with virus elimination and permanent cure, hence in clinical practice is the main therapeutic aim (6).

The general treatment involves no consumption of alcohol as it aggravates the damage to the liver and increases the rate of progression of cirrhosis. Patients diagnosed with viral hepatitis $\mathrm{C}$ and susceptible to viral hepatitis A or B should be immunized against hepatitis A virus (HAV) and hepatitis B virus (HBV). For obese patients (BMI > $25 \mathrm{~kg} / \mathrm{m}^{2}$ ), a body mass reduction program should be implemented. In the first place, patients with advanced viral hepatitis (fibrosis $>1$ on a scale of 1 to 5 , patients waiting for liver transplantation or after liver transplantation due to $\mathrm{HCV}$ reactivation, hemodialyzed patients, HBV- or HIV-positive patients and patients with extrahepatic manifestations of HCV infection should be qualified for treatment (7).

Treatment of patients with HCV genotype 1 infection: three-drug therapy: pegylated alpha interferon + ribavirin + sofosbuvir/simeprevir/daclatasvir (PegINF alpha $+\mathrm{RBV}+\mathrm{SOF} / \mathrm{SMV} / \mathrm{DCV})$ or boceprevir/telaprevir (BOC/TVR) - if the former drugs are unavailable) or two-drug therapy: (SOF + SMV, SOF + DCV or SOF + RBV) (8).

\section{Purpose}

The assessment of the safety profile of ombitasvir/paritaprevir/ritonavir+dasabuvir in adult chronic hepatitis $\mathrm{C}$ patients with confirmed $\mathrm{HCV}$ genotype 1 presence.

\section{MATERIAL AND METHODS}

The search for clinical trials was based on a detailed protocol developed before the commencement of a systematic overview in accordance with the Cochrane Collaboration guidelines (9). It included the criteria of inclusion into the overview, the search strategy, the method for selecting trials and the planned methodology for data analysis and synthesis.

The analysis included clinical trials meeting the criteria concerning:

- population: adult patients with chronic genotype 1 hepatitis $\mathrm{C}$,

- intervention: $3 \mathrm{D} \pm \mathrm{RBV}$ - ombitasvir/paritaprevir/ritonavir + dasabuvir $\pm \mathrm{RBV}$ in people with genotype 1 infection;

- alternative technologies (comparators): no treatment (placebo),

- methodology: blinded or unblinded randomized clinical trials,

- endpoints, safety: (general, serious, specific) adverse events, removal from the trial due to adverse events, deaths.

The following sources of medical information were searched in order to find primary clinical trials: Medline (via PubMed), Embase, Biomed Central (via PubMed), The Cochrane Library (Central), registries of clinical trials (ClinicalTrials.gov), Centre for Reviews and Dissemination. The database was last searched on 15-16 February 2016. Additionally, the most important safety-related information from Viekirax SmPC (10) (paritaprevir/ritonavir, ombitasvir) and Exviera SmPC (11) (dasabuvir) were included.

In the trials with a control group, the results of a statistical analysis performed by the study authors 
were presented (they were based on the primary data and thus considered a reliable source of information). In all the cases, data for the longest possible observation period were analyzed. No meta-analysis was performed and the results of each study were presented separately.

\section{RESULTS}

The safety profile of the $3 \mathrm{D}$ regimen, as compared to placebo, was evaluated in two randomized, multi-center, double-blinded phase III clinical trials in which the study population included untreated patients (SAPPHIRE I) or patients after unsuccessful therapy (SAPPHIRE II), with genotype 1 infection. The analysis included the total number of adverse events, serious adverse events and specific adverse events occurring in at least $10 \%$ of the patients as well as the most important parameters underlying the assessment of the effects of the therapy on the liver.
Patients without prior treatment - SAPPHIRE I

The prevalence of the reported adverse events was in general statistically significantly greater in the group on therapy $3 \mathrm{D}+\mathrm{RBV}$ compared to the placebo group $(\mathrm{RR}=1.19$ [1.08; 1.32]). No statistically significant differences were observed in relation to the risk of serious adverse events or therapy discontinuance due to adverse events.

During the $3 \mathrm{D}+\mathrm{RBV}$ therapy, the placebo group was statistically significantly more frequently observed to have nausea, insomnia, diarrhea, itching, and asthenia. During the 3D+RBV therapy, the percentage of patients with ALT increase at level 3 or 4 was statistically significantly lower compared to the placebo group (12).

\section{Patients after unsuccessful therapy - SAPPHIRE II}

The prevalence of the reported adverse events was statistically significantly greater in the group on therapy $3 \mathrm{D}+\mathrm{RBV}$ compared to the placebo group $(\mathrm{RR}=1.11$ $[1.00 ; 1.22])$. During the $3 \mathrm{D}+\mathrm{RBV}$ itching was statis-

Table 1. Risk of adverse events to compare 3D + RBV therapy and placebo in the population of untreated patients with genotype $1 \mathrm{HCV}$ infection and without liver cirrhosis - SAPPHIRE I.

\begin{tabular}{|c|c|c|c|c|c|c|}
\hline End point & Clinical trial & $\begin{array}{c}\text { 3D + RBV } \\
\mathrm{n} / \mathrm{N}(\%)\end{array}$ & $\begin{array}{c}\text { PLC } \\
\mathrm{n} / \mathrm{N}(\%)\end{array}$ & $\mathrm{RR}(95 \% \mathrm{CI})$ & $\mathrm{NNH} / \mathrm{RD}(95 \% \mathrm{CI})$ & $\mathrm{p}$ \\
\hline Total AE & SAPPHIRE I & $414 / 473(87.5 \%)$ & $116 / 158(73.4 \%)$ & $1.19(1.08 ; 1.32)$ & $\mathrm{NNH}=7(4 ; 15)$ & $<0.001$ \\
\hline Total SAE & SAPPHIRE I & $10 / 473(2.1 \%)$ & $0 / 158(0.0 \%)$ & $7.04(0.42 ; 119.53)$ & $\mathrm{NNH}=47(27 ; 189)$ & 0.074 \\
\hline $\begin{array}{c}\text { Therapy } \\
\text { discontinued } \\
\text { due to } \mathrm{AE}\end{array}$ & SAPPHIRE I & $3 / 473(0.6 \%)$ & $1 / 158(0.6 \%)$ & $1.00(0.10 ; 9.56)$ & $\mathrm{RD}=0.00001(-0.01 ; 0.01)$ & NS \\
\hline \multicolumn{7}{|c|}{ Specific AE ( $\geq 10 \%$ of patients) } \\
\hline Fatigue & SAPPHIRE I & $164 / 473(34.7 \%)$ & $45 / 158(28.5 \%)$ & $1.22(0.92 ; 1.60)$ & $\mathrm{RD}=0.06(-0.02 ; 0.14)$ & NS \\
\hline Headache & SAPPHIRE I & $156 / 473(33 \%)$ & $42 / 158(26.6 \%)$ & $1.24(0.93 ; 1.66)$ & $\mathrm{RD}=0.06(-0.02 ; 0.14)$ & NS \\
\hline Nausea & SAPPHIRE I & $112 / 473(23.7 \%)$ & $21 / 158(13.3 \%)$ & $1.78(1.16 ; 2.74)$ & $\mathrm{NNH}=9(5 ; 25)$ & 0.005 \\
\hline Itching & SAPPHIRE I & $80 / 473(16.9 \%)$ & $6 / 158(3.8 \%)$ & $4.45(1.98 ; 10.01)$ & $\mathrm{NNH}=7(5 ; 11)$ & $<0.001$ \\
\hline Insomnia & SAPPHIRE I & $66 / 473(14 \%)$ & $12 / 158(7.6 \%)$ & $1.84(1.02 ; 3.31)$ & $\mathrm{NNH}=15(8 ; 84)$ & 0.036 \\
\hline Diarrhea & SAPPHIRE I & $65 / 473(13.7 \%)$ & $11 / 158(7.0 \%)$ & $1.97(1.07 ; 3.64)$ & $\mathrm{NNH}=14(8 ; 57)$ & 0.024 \\
\hline Asthenia & SAPPHIRE I & $57 / 473(12.1 \%)$ & $6 / 158(3.8 \%)$ & $3.17(1.40 ; 7.22)$ & $\mathrm{NNH}=12(8 ; 24)$ & 0.002 \\
\hline Rash & SAPPHIRE I & $51 / 473(10.8 \%)$ & 9/158 (5.7\%) & $1.89(0.95 ; 3.76)$ & $\mathrm{NNH}=19(10 ; 193)$ & NS \\
\hline Muscle pain & SAPPHIRE I & $23 / 297(7.7 \%)$ & $10 / 97(10.3 \%)$ & $0.75(0.37 ; 1.52)$ & $\mathrm{RD}=-0.03(-0.09 ; 0.04)$ & NS \\
\hline \multicolumn{7}{|c|}{ Impact on liver } \\
\hline $\begin{array}{c}\text { ALT at level } \\
3 \text { or } 4\end{array}$ & SAPPHIRE I & $4 / 469(0.9 \%)$ & $7 / 158(4.4 \%)$ & $0.19(0.06 ; 0.65)$ & $\mathrm{NNH}=28[15 ; 381]$ & 0.007 \\
\hline $\begin{array}{c}\text { AST at level } \\
3 \text { or } 4\end{array}$ & SAPPHIRE I & $3 / 469(0.6 \%)$ & $3 / 158(1.9 \%)$ & $0.34(0.07 ; 1.65)$ & $\mathrm{RD}=-0.01(-0.04 ; 0.01)$ & bd \\
\hline $\begin{array}{r}\text { Total bilirubin } \\
\text { at level } 3 \text { or } 4\end{array}$ & SAPPHIRE I & $13 / 469(2.8 \%)$ & $0 / 158(0.0 \%)$ & $9.13(0.55 ; 152.77)$ & $\mathrm{NNH}=36(22 ; 97)$ & 0.046 \\
\hline
\end{tabular}

Source: Analysis based on Feld et al. (12) 
tically significantly more frequently reported in the placebo group. Compared to the other adverse events, no statistically significant differences were observed between the 3D + RBV therapy and placebo (13).

Information based on the Viekirax (paritaprevir/ritonavir, ombitasvir) SmPC (10).

Viekirax is not recommended for use in monotherapy. In hepatitis $\mathrm{C}$ treatment, it must always be used in combination with other medicinal products.

The efficacy of Viekirax was not observed in patients previously treated with Viekirax or medicinal products of the same class (NS3/4A or NS5A inhibitors).

Caution is advised when using Viekirax in patients with compensated liver cirrhosis with HCT GT4 infection - given that no trials were conducted for this population, no optimum treatment period has been established. There are also no data about the safety of use and the efficacy of this medicinal product in patients infected with HCV virus genotypes other than GT1 or 4, or data concerning the concomitant use with anti-viral drugs other than dasabuvir and/or ribavirin. No data are available on renewed treatment with Viekirax or treatment after unsuccessful therapy with drugs of the same group (NS3/4A or NS5A inhibitors).

Data concerning the use of Viekirax during pregnancy and breast-feeding in humans are limited and therefore it is not recommended for use by pregnant or breast-feeding women. The intervention was observed to have no adverse effects on reproduction or fetus development in animal studies. In the case of using the medicinal product Viekirax in combination with $\mathrm{RBV}$ in female patients of childbearing age or their partners, special care should be exercised to prevent pregnancy on account of strong embryotoxic and/or teratogenic effects of RBV.

Table 2. Risk of adverse events to compare 3D+RBV therapy and placebo in the population of patients after unsuccessful two-drug therapy with genotype $1 \mathrm{HCV}$ infection and without liver cirrhosis - SAPPHIRE II.

\begin{tabular}{|c|c|c|c|c|c|c|}
\hline End point & Clinical trial & $\begin{array}{c}3 \mathrm{D}+\mathrm{RBV} \\
\mathrm{n} / \mathrm{N}(\%)\end{array}$ & $\begin{array}{c}\text { PLC } \\
\mathrm{n} / \mathrm{N}(\%)\end{array}$ & $\mathrm{RR}(95 \% \mathrm{CI})$ & $\mathrm{NNH} / \mathrm{RD}(95 \% \mathrm{CI})$ & $\mathrm{p}$ \\
\hline Total AE & SAPPHIRE II & $271 / 297(91.2 \%)$ & $80 / 97(82.5 \%)$ & $1.11(1.00 ; 1.22)$ & $\mathrm{NNH}=11(5 ; 181)$ & 0.023 \\
\hline Total SAE & SAPPHIRE II & $6 / 297(2.0 \%)$ & $1 / 97(1.0 \%)$ & $1.96(0.24 ; 16.08)$ & $\mathrm{RD}=0.01(-0.02 ; 0.04)$ & NS \\
\hline $\begin{array}{c}\text { Therapy } \\
\text { discontinued } \\
\text { due to } \mathrm{AE}\end{array}$ & SAPPHIRE II & $3 / 297(1.0 \%)$ & $0 / 97(0.0 \%)$ & $2.30(0.12 ; 44.18)$ & $\mathrm{RD}=0.01(-0.01 ; 0.03)$ & NS \\
\hline \multicolumn{7}{|c|}{ Specific $\mathrm{AE}(\geq 10 \%$ of patients) } \\
\hline Fatigue & SAPPHIRE II & 99/297 (33.3\%) & $22 / 97(22.7 \%)$ & $1.47(0.98 ; 2.19)$ & $\mathrm{NNH}=9(4 ; 134)$ & 0.057 \\
\hline Headache & SAPPHIRE II & $108 / 297(36.4 \%)$ & $34 / 97(35.1 \%)$ & $1.04(0.76 ; 1.41)$ & $\mathrm{RD}=0.01(-0.10 ; 0.12)$ & NS \\
\hline Nausea & SAPPHIRE II & $60 / 297(20.2 \%)$ & $17 / 97(17.5 \%)$ & $1.15(0.71 ; 1.88)$ & $\mathrm{RD}=0.03(-0.06 ; 0.12)$ & NS \\
\hline Itching & SAPPHIRE II & $41 / 297(13.8 \%)$ & $5 / 97(5.2 \%)$ & $2.68(1.09 ; 6.59)$ & $\mathrm{NNH}=11(6 ; 36)$ & 0.027 \\
\hline Insomnia & SAPPHIRE II & $42 / 297(14.1 \%)$ & $7 / 97(7.2 \%)$ & $1.96(0.91 ; 4.22)$ & $\mathrm{NNH}=14(7 ; 234)$ & 0.078 \\
\hline Diarrhea & SAPPHIRE II & $39 / 297(13.1 \%)$ & $12 / 97(12.4 \%)$ & $1.06(0.58 ; 1.94)$ & $\mathrm{RD}=0.01(-0.07 ; 0.08)$ & NS \\
\hline Asthenia & APPHIRE II & $47 / 297(15.8 \%)$ & $11 / 97(11.3 \%)$ & $1.40(0.75 ; 2.58)$ & $\mathrm{RD}=0.04(-0.03 ; 0.12)$ & NS \\
\hline Dyspnea & SAPPHIRE II & $37 / 297(12.5 \%)$ & $10 / 97(10.3 \%)$ & $1.21(0.62 ; 2.34)$ & $\mathrm{RD}=0.02(-0.05 ; 0.09)$ & NS \\
\hline Muscle pain & SAPPHIRE II & $23 / 297(7.7 \%)$ & $10 / 97(10.3 \%)$ & $0.75(0.37 ; 1.52)$ & $\mathrm{RD}=-0.03(-0.09 ; 0.04)$ & NS \\
\hline Cough & SAPPHIRE II & $32 / 297(10.8 \%)$ & $5 / 97(5.2 \%)$ & $2.09(0.84 ; 5.21)$ & $\mathrm{RD}=0.06(-0.0002 ; 0.11)$ & NS \\
\hline \multicolumn{7}{|c|}{ Impact on liver } \\
\hline $\begin{array}{c}\text { ALT at level } \\
3 \text { or } 4\end{array}$ & SAPPHIRE II & $5 / 296(1.7 \%)$ & $3 / 96(3.1 \%)$ & $0.54(0.13 ; 2.22)$ & $\mathrm{RD}=-0.01(-0.05 ; 0.02)$ & NS \\
\hline $\begin{array}{c}\text { AST at level } \\
3 \text { or } 4\end{array}$ & SAPPHIRE II & $3 / 296(1 \%)$ & $1 / 96(1 \%)$ & $0.97(0.10 ; 9.24)$ & $\mathrm{RD}=-0.0003(-0.02 ; 0.02)$ & NS \\
\hline $\begin{array}{c}\text { Total bilirubin } \\
\text { at level } 3 \text { or } 4\end{array}$ & SAPPHIRE II & $7 / 296(2.4 \%)$ & $0 / 96(0.0 \%)$ & $4.90(0.28 ; 84.99)$ & $\mathrm{NNH}=42(21 ; 1229)$ & NS \\
\hline
\end{tabular}

Source: Analysis based on Zeuzem et al. (13) 
Table 3. Prevalence of adverse events as observed during Viekirax-based treatment.

\begin{tabular}{|c|c|c|}
\hline \multirow[b]{2}{*}{ Frequency } & \multicolumn{2}{|c|}{ Adverse events } \\
\hline & $\begin{array}{c}\text { Viekirax + dasabuvir + RBV } \\
(\mathrm{N}=2,044)^{*}\end{array}$ & $\begin{array}{c}\text { Viekirax + dasabuvir } \\
(\mathrm{N}=588)\end{array}$ \\
\hline Very common $(\geq 1 / 10)$ & Insomnia, nausea, itching, asthenia, fatigue & - \\
\hline Common $(\geq 1 / 100$ to $<1 / 10)$ & Anemia & Itching \\
\hline
\end{tabular}

*Data for all participants with genotype 1 virus, including patients with liver cirrhosis, in phase II and III trials. Source: Analysis based on Viekirax SmPC (10)

Table 4. Prevalence of adverse events as observed during dasabuvir-based treatment.

\begin{tabular}{|c|c|c|}
\hline \multirow[b]{2}{*}{ Frequency } & \multicolumn{2}{|l|}{ Adverse events } \\
\hline & $\begin{array}{l}\text { Viekirax + dasabuvir + RBV } \\
(\mathrm{N}=2,044)^{*}\end{array}$ & $\begin{array}{c}\text { Viekirax + dasabuvir } \\
(\mathrm{N}=588)\end{array}$ \\
\hline Very common $(\geq 1 / 10)$ & Insomnia, nausea, itching, asthenia, fatigue & - \\
\hline Common $(\geq 1 / 100$ to $<1 / 10)$ & Anemia & Itching \\
\hline
\end{tabular}

*Data for all participants with genotype 1 virus, including patients with liver cirrhosis, in phase II and III trials. Source: Analysis based on Exviera SmPC (11)

Viekirax is not recommended for concomitant use with lopinavir/ritonavir or atazanavir/ritonavir (in the case of atazanavir, also when Viekirax is used without dasabuvir). Additionally, given the risk of increase in rilpivirine concentration, it is not recommended for concomitant use with the product in question (Viekirax SmPC) (10).

\section{Information from the Exviera (dasabuvir) SmPC (11).}

Exviera is not recommended for use in monotherapy. In hepatitis $\mathrm{C}$ treatment, it must always be used in combination with other medicinal products.

The efficacy of dasabuvir was not observed in patients previously exposed to dasabuvir or medicinal products of anticipated cross-resistance.

The efficacy of dasabuvir was not determined for patients infected with $\mathrm{HCV}$ of genotype other than GT1 and no data were collected on using dasabuvir with antivirals other than ombitasvir/paritaprevir/ritonavir and/or RBV - dasabuvir should not be used in patients infected with HCV of a different genotype and in combination with other antivirals.

No data are available on renewed treatment with dasabuvir or medicinal products of anticipated cross-resistance.

Data concerning the use of dasabuvir during pregnancy and breast-feeding in humans are limited and therefore it is not recommended for use by pregnant or breast-feeding women. The intervention was observed to have no adverse effects on reproduction or fetus development in animal studies. If dasabuvir is used in combination with RBV in female patients of childbearing age or their partners, special care should be exercised to prevent pregnancy on account of the strong embryotoxic and/or teratogenic effects of RBV (Exviera SmPC) (11).

In addition, 7 studies on the safety assessment of schemas containing ombitasvir / paritaprevir / ritonavir + dasabuvir have been identified:

- 3 RCTs for comparison of the 3D + RBV vs 3D scheme (PEARL II, PEARL III, PEARL IV),

- 1 RCT for comparison of 3D + RBV (12 weeks) vs 3D + RBV (24 weeks) (TURQUOISE II),

- 2 RCTs for comparison of 3D \pm RBV vs TVR (Telaprevir) + PR (PegIFN $\alpha$ + RBV) (MALACHITE I, MALACHITE II),

- 1 nRCT study for the 3D + RBV scheme (Lalezari 2014).

It has been shown that compared to TVR triple therapy: $3 \mathrm{D} \pm \mathrm{RBV}$ therapy is associated with significantly statistically and clinically lower risk of: total adverse events, serious adverse events, anemia, asthenia, muscle pain, fever, alopecia, neutropenia, nausea, drop Appetite, pruritus, pruritus, rash, dizziness, fatigue. In both the untreated patients and the failure of dual therapy, the risk of adverse events was higher in patients treated with $\mathrm{RBV}$-containing regimens than without RBV, although the risk of serious adverse events was low and comparable in both groups. The most common adverse events during treatment included fatigue, 
headache, asthenia, nausea, pruritus, insomnia, diarrhea, and rash (14-21).

\section{DISCUSSION}

The purpose of the analysis was to assess the safety profile of ombitasvir/paritaprevir/ritonavir+dasabuvir in adult patients with chronic hepatitis $\mathrm{C}$ and confirmed HCV genotype 1 infection.

The assessment concerned the $3 \mathrm{D} \pm \mathrm{RBV}$ therapy used for 12 or 24 weeks in people with genotype 1 infections.

Viral hepatitis $\mathrm{C}$ is a highly varied disease due to the diversity of the etiological agent, ie $\mathrm{HCV}$, which occurs in the form of 6 main types (genotype 1-6 $\mathrm{HCV}$ ) with a different distribution in the population and a different response to therapy. Genotype 2 and 3 $\mathrm{HCV}$ is characterized by a relatively high susceptibility to treatment by standard therapy based on PegIFN $\alpha$ and RBV, and the percentage of patients achieving permanent recovery (SVR24) is estimated at $87 \%$ and $77 \%$ of patients for genotype 2 and 3 respectively. At the same time, in patients with genotype 1 or 4 infections, the percentage of permanent response to treatment is significantly lower and equal to $45 \%$ and $56 \%$ respectively. For a long time, the standard therapy based on PegIFN $\alpha$ plus RBV was the only available therapeutic option for hepatitis C patients. New three-drug therapies with BOC or TVR, available from 2011, have increased the likelihood of successful treatment up to $61-75 \%$ for TVR in the population of non-treated patients and $51-66 \%$ in the group of patients after unsuccessful two-drug therapy based on PegIFN $\alpha+$ RBV, as well as 54-75\% and 59$67 \%$ for BOC in the population of non-treated patients and patients after unsuccessful therapy based on PegIFN $\alpha+R B V$, respectively (22). Additionally, BOC and TVR can only be used in patients with genotype 1 infection. Therapies recommended in the most recent guidelines and registered in the EU allow achieving SVR of $90-100 \%$. Therapies of such high efficiency include interferon-free therapies (paritaprevir/ritonavir + ombitasvir and dasabuvir) used for the recommended therapeutic regimens (Telaprevir SmPC, Boceprevir SmPC) $(23,24)$.

The safety analysis showed that interferon-free drugs (paritaprevir/ritonavir + ombitasvir and dasabuvir) are characterized by a more favorable safety profile and the adverse events observed during the therapy were mostly mild or moderate. The low percentage of patients who required that the therapy be discontinued due to adverse events should also be emphasized. The results of a direct comparative analysis show that the application of the $3 \mathrm{D}+\mathrm{RBV}$ therapy, as compared to the placebo group, involved a statistically significantly higher risk of general adverse events, nausea, insomnia, diarrhea, itching, and asthenia.

Given the growing number of people with chronic hepatitis $\mathrm{C}$ and requiring therapy, there is a need to implement new therapeutic options of high efficiency and favorable safety profile. Recently, a number of new DAA drugs (daclatasvir, sofosbuvir, simeprevir, ledipasvir/sofosbuvir) have been introduced which can be used both in combination with PegIFN $\alpha+$ RBV and in non-IFN regimens. The efficacy of ombitasvir/paritaprevir/ritonavir + dasabuvir is high and ranges from $80 \%$ up to $100 \%$, and their safety profile is also acceptable.

\section{CONCLUSIONS}

Ombitasvir/paritaprevir/ritonavir+dasabuvir provide a safe therapeutic option in the population of adult patients with chronic genotype 1 hepatitis $\mathrm{C}$, both those untreated and after unsuccessful twodrug PegIFN $\alpha$-based therapy, patients with HIV coinfection and patients after liver transplantation.

Given that both drugs are used in interferonfree therapies, they may be used in patients with contraindications to or intolerance of interferon.

The authors declare no conflict of interests.

\section{REFERENCES}

1. Szczeklik A.: Choroby wewnętrzne. Stan wiedzy na rok 2011. Wydawnictwo Medycyna Praktyczna, Kraków 2011.

2. http://www.gwiazdanadziei.pl/download/raport_komisji_zdrowia.pdf (accessed on 22.05. 2018).

3. https://ecdc.europa.eu/en/publications-data/ hepatitis-c-annual-epidemiological-report-2015 (accessed on 22.05.2018).

4. http://www.hcv.pzh.gov.pl/ (accessed on 22.05.2018).

5. Flisiak R., Pogorzelska J., Berak H., Horban A., Orłowska I. et al.: Clin. Exp. Hepatol. 2, 144 (2016).

6. http://www.pasl.pl/wp-content/uploads/2014/ 10/Rekomendacje-PGE-HCV-20162.pdf (22.05.2018).

7. http://www.who.int/hiv/pub/hepatitis/hepatitisc-guidelines/en/ (accessed on 30.09.2017).

8. http://www.hcvguidelines.org/fullreport (accessed on 01.10.2017).

9. Higgins J.P.T., Green S. (Eds.): Cochrane Handbook for Systematic Reviews of Interven- 
tions Version 5.1.0 (updated March 2011). The Cochrane Collaboration in London, 2011.

10. http://www.ema.europa.eu/ema/index.jsp? curl=pages/medicines/human/medicines/ 003839/human_med_001838.jsp\&mid=WC0b 01ac058001d124. (accessed on 30.11.2017).

11. http://www.ema.europa.eu/ema/index.jsp? curl=pages/medicines/human/medicines/ 003837/human_med_001833.jsp\&mid=WC0b 01ac058001d124. (accessed on 30.10.2017).

12. Feld J.J., Kowdley K.V., Coakley E., Sigal S., Nelson D.R. et al.: N. Engl. J. Med. 370, 1594 (2014).

13. Zeuzem S., Jacobson I.M., Baykal T., Marinho R.T., Poordad F. et al.: N. Engl. J. Med. 370, 1604 (2014).

14. Feld J.J., Kowdley K.V., Coakley E., Sigal S., Nelson D.R. et al.: N. Engl. J. Med. 370, 1594 (2014).

15. Ferenci P., Bernstein D., Lalezari J., Cohen D., Luo Y. et al.: N. Engl. J. Med. 370, 1983 (2014).

16. Zeuzem S., Jacobson I.M., Baykal T., Marinho R.T., Poordad F. et al.: N. Engl. J. Med. 370, 1604 (2014).

17. Andreone P., Colombo M.G., Enejosa J.V., Koksal I., Ferenci P., Maieron A. et al.: Gastroenterology 147, 359 (2014).
18. Poordad F., Hezode C., Trinh R., Kowdley K.V., Zeuzem S. et al.: N. Engl. J. Med. 370, 1973 (2014).

19. NCT01854697, A Study to Evaluate the Efficacy and Safety of Three Experimental Drugs Compared With Telaprevir (a Licensed Product) in People With Hepatitis C Virus Infection Who Have Not Had Treatment Before (MALACHITE 1).

20. NCT01854528, A Study to Evaluate the Efficacy and Safety of Three Experimental Drugs Compared With Telaprevir (a Licensed Product) for Treatment of Chronic Hepatitis C Infection in Treatment-experienced Adults.

21. NCT01911845, An Open-label, Single Arm, Phase 2 Study to Evaluate ABT-450/r/ABT-267 and ABT-333 With Ribavirin (RBV) in Adults With Genotype 1 HCV Infection Taking Methadone or Buprenorphine.

22. Park C., Jiang S., Lawson K.A.: J. Clin. Pharm. Ther. 39, 14 (2014).

23. http://www.ema.europa.eu/docs/pl_PL/document_library/EPAR_-_Product_Information/ human/002313/WC500115529.pdf. (accessed on 23.09.2017).

24. http://www.ema.europa.eu/docs/pl_PL/document_library/EPAR_-_Product_Information/ human/002332/WC500109786.pdf. (accessed on 30.09.2017).

Received: 2.05.2018 